\title{
Changes in pulsatile secretion patterns of LH, FSH, progesterone, androstenedione and oestradiol in cows after superovulation with PMSG
}

\author{
M. M. Bevers, S. J. Dieleman, H. T. M. van Tol, D. M. Blankenstein and \\ J. van den Broek
}

Department of Herd Health and Reproduction, Veterinary Faculty, University of Utrecht, Yalelaan 7,3584 CL Utrecht, The Netherlands

\begin{abstract}
Summary. Six heifers were injected i.m. with 2500 i.u. PMSG followed by $15 \mathrm{mg}$ prostaglandin $48 \mathrm{~h}$ later. Serial blood samples were collected through a catheter in the caudal vena cava every $10 \mathrm{~min}$ for $8 \mathrm{~h}$ on Day 10 ( $7 \mathrm{~h}$ after PMSG administration), during luteal regression ( $7 \mathrm{~h}$ after prostaglandin administration) and on the day thereafter. Four normally cyclic heifers served as a control group. Concentrations of progesterone, androstenedione, oestradiol, LH, FSH, and PMSG in the vena cava samples were measured and the frequency and amplitudes of episodic pulses of all hormones were estimated except for PMSG. Ovaries were collected by ovariectomy at $50 \mathrm{~h}$ after onset of luteal regression to determine the number of preovulatory follicles (non-atretic follicles $\geqslant 10 \mathrm{~mm}$ ).
\end{abstract}

Stimulation of follicular growth by administration of PMSG resulted in the following effects on the secretion of steroids and endogenous gonadotrophins. (1) There were no alterations in progesterone concentration and the amplitude and frequency of episodic pulses. Mean ( \pm s.e.m.) concentrations were $54 \cdot 1 \pm 5 \cdot 8$, $19.1 \pm 3.1$ and $3.4 \pm 0.9 \mathrm{nmol} / 1$ on Day $10(\mathrm{~L})$, during luteal regression (LR) and on the day thereafter (F) respectively. (2) There were no alterations in the episodic secretion patterns of androstenedione. Mean concentrations were $0.20 \pm 0.02$, $0.15 \pm 0.02$ and $0.11 \pm 0.02 \mathrm{nmol} / 1$ for the $L, L R$ and $F$ periods respectively. (3) There was an increase in oestradiol concentration from $17 \cdot 1 \pm 3.0 \mathrm{pmol} / 1$ during the $\mathrm{L}$ period to $233.7 \pm 86.4 \mathrm{pmol} / 1$ during the $\mathrm{F}$ period. Pulse amplitude was enhanced compared to corresponding periods in control animals whereas pulse frequency remained the same. The oestradiol concentration was significantly correlated with the number of preovulatory follicles $(r=0.82, P<0.05)$. (4) There was a suppression of the frequency of episodic LH pulses $(/ 8 \mathrm{~h})$ during the LR $(3 \cdot 2 \pm 0 \cdot 7)$ and F $(4 \cdot 3 \pm 0.4)$ periods compared to corresponding periods in control heifers $(9.5 \pm 0.9$ and $7.0 \pm 1.5$ respectively). The preovulatory LH peak occurred earlier in 4 of 6 treated heifers. (5) There was a suppression of FSH concentrations, pulse amplitude and frequency during the $L R$ and $F(17.4 \pm 0.9 \mathrm{mg} / 1,4.7 \pm 0.8 \mu \mathrm{g} / 1$ and $7.5 \pm 0.4$ pulses $/ 8 \mathrm{~h})$ periods compared to the corresponding F-period values $(35.6 \pm 6.2 \mathrm{mg} / 1,9.8 \pm 1.6 \mu \mathrm{g} / \mathrm{l}$ and $9 \cdot 3 \pm 0 \cdot 3$ pulses $/ 8 \mathrm{~h}$ ) in control heifers.

It is concluded that the increased number of preovulatory follicles after PMSG administration severely suppresses endogenous FSH secretion by means of enhanced concentrations of oestradiol and probably also of inhibin. 


\section{Introduction}

Administration of pregnant mare serum gonadotrophin (PMSG) during the luteal phase is a widely used procedure to increase the ovulation rate in the cow with the ultimate purpose of increasing the number of embryos suitable for embryo transplantation. A main drawback of the method is the high variation in the number of viable embryos and the variability of the response to the PMSG injection in terms of number of ovulations. Part of the variation can be attributed to the total number of growing follicles in the ovaries before treatment (Monniaux et al., 1983). However, differential effects of PMSG on the presumptive preovulatory follicles also contribute to the variability of the ovulation rate. It can be assumed that PMSG profoundly interferes with the ovarian-hypothalamic-pituitary axis and intraovarian regulation mechanisms, due to the long half-life of the hormone and to the fact that it has follicle-stimulating hormone (FSH) and luteinizing hormone (LH) activity (Schams et al., 1978).

These properties are not only beneficial but also negatively affect the normal sequence of physiological events of follicular development and oocyte maturation. Neutralization of PMSG after the preovulatory LH peak by a monoclonal antibody increases the ovulation rate (Dieleman \& Bevers, 1987; Dieleman et al., 1989). However, abberations in follicular development (Dieleman \& Kruip, 1980; Moor et al., 1984; Callesen et al., 1987) and in hormone profiles in the peripheral blood (Saumande, 1980; Bevers \& Dieleman, 1987) do occur in the period between the administration of PMSG and the preovulatory LH peak. In 15-20\% of PMSG-stimulated cows the LH peak is not even elicited (Bevers \& Dieleman, 1987; Callesen et al., 1987).

In this study, we investigated the pulsatile secretion patterns of gonadotrophic hormones and of steroids to obtain a better understanding of the mechanisms by which PMSG acts. Preliminary results have been published (Bevers et al., 1988a).

\section{Materials and Methods}

Animals and experimental design. Experiments were performed with 10 Dutch-Friesian heifers weighing between 300 and $350 \mathrm{~kg}$. They were started after at least one oestrous cycle indoors with normal luteal function and oestrus.

At $02: 00$ h on Day 10 (Day $0=$ day of first standing oestrus), 6 randomly chosen heifers were injected i.m. with 2500 i.u. PMSG (Folligon: Intervet International bv, Boxmeer, The Netherlands) followed by an i.m. injection of $15 \mathrm{mg}$ prostaglandin F-2 $\alpha$ (Prosolvin: Intervet International bv) $48 \mathrm{~h}$ later. The other 4 heifers served as a control group of cyclic heifers in which the normal course of follicle development was not affected by exogenous gonadotrophins and/or prostaglandins (PG).

All heifers were ovariectomized $50 \mathrm{~h}$ after onset of luteal regression. Onset of luteai regression in the control heifers, defined as the time after which the progesterone decreased in at least 3 successive samples (Dieleman et al., 1986), was assessed by estimating the progesterone concentration in the peripheral blood with a rapid radioimmunoassay (RIA) (Dieleman et al., 1983a). At Day 5 of the treatment cycle a catheter was surgically inserted in all heifers as previously described (Bevers et al., 1988b). The tip of the catheter was located in the vena cava near the bifurcation with the vena ovarica. Correct placing was assessed according to Walters et al. (1984) by estimating the progesterone concentration with the rapid RIA. From Day I jugular venous blood samples were taken by venepuncture each day at 01:00,07:00, 13:00 and 19:00 $\mathrm{h}$ until Day 14 and thereafter at 03:00,07:00,11:00, 15:00, 19:00 and 23:00 h. Serial blood samples were collected via the catheter every $10 \mathrm{~min}$ for an 8-h period at Day $10(6 \mathrm{~h}$ after the administration of PMSG), at Day 12 (6 h after the administration of PG) and the day thereafter. Control heifers were sampled similarly on Day 10, during luteal regression and on the day thereafter. Blood was collected in heparinized tubes, immediately cooled and centrifuged, and plasma was stored at $-25^{\circ} \mathrm{C}$ until analysis.

Radioimmunoassays. All serial samples from each animal were estimated in a single assay to reduce variations.

Plasma concentrations of progesterone and oestradiol were estimated by direct solid phase ${ }^{125}$ I RIA methods (Coat-A-Count TKPG and Coat-A-Count TKE, respectively; Diagnostic Products Corporation, Los Angeles, CA, USA) according to the manufacturer as previously validated (Dieleman \& Bevers, 1987). The sensitivity was $0.15 \mathrm{nmol} / 1$ for the progesterone and $7.5 \mathrm{pmol} / 1$ for the oestradiol RIA. The interassay coefficients of variation were $<11 \%$.

Concentrations of androstenedione were estimated by a solid-phase ${ }^{125}$ I RIA method (Coat-A-Count TKA; Diagnostic Products Corporation) according to the manufacturer with slight modifications. Plasma samples of $1 \mathrm{ml}$ were extracted once with $2 \mathrm{ml}$ diethyl ether (Analar quality; BDH, Poole, UK). After evaporation of the solvent under 
a nitrogen stream, the residues were dissolved in $500 \mu$ buffer (Diagnostic Products Corporation) by sonification during $5 \mathrm{~min}$, and $200 \mu \mathrm{l}$ in duplicate were assayed. The recovery was established by extracting 5 parallel samples to which 10000 d.p.m. tritiated androstenedione had been added (mean recovery: $98 \cdot 1 \pm 4 \cdot 2$ (s.d.) $\%$ for 15 assays). The main cross-reactivities were $9.4,7 \cdot 4,1.3$ and $0.7 \%$ for androsterone, dehydroepiandrosterone, oestrone and testosterone respectively, and $<0.5 \%$ for steroids of interest according to the manufacturer. The sensitivity was $0.04 \mathrm{nmol} / \mathrm{l}$ and the interassay coefficient of variation was $12 \%(n=15)$. A mean recovery of $103 \pm 9 \%(n=20)$ was obtained for the comparison of the androstenedione concentrations as estimated by this RIA method with those estimated by the method described previously (Dieleman et al., 1983b).

Plasma concentrations of FSH were estimated as described by Cheng (1978) and validated in our laboratory (Dieleman et al., 1983b). Plasma concentrations of LH and PMSG were estimated by previously validated RIA methods (Dieleman et al., 1983b; Bevers \& Dieleman, 1987). The intra- and interassay coefficients of variation for the FSH, LH and PMSG RIA were $<9$ and $<13 \%$ respectively. The sensitivities were $0.4 \mu \mathrm{g}$ bFSH HS-2-17/l, $0.4 \mu \mathrm{g}$ NIH-LH-B4/1, 0.3 $\mu$ g PMSG-PM23/1 for the RIA of FSH, LH and PMSG respectively. Cross-reactions of PMSG in the homologous RIAs of bLH and bFSH were $<0.2 \%$ and $<0.06 \%$ respectively.

Collection and dissection of follicles. Ovaries were collected by ovariectomy (Dieleman et al., 1983a) at $50 \mathrm{~h}$ after the onset of luteal regression. Follicles $>5 \mathrm{~mm}$ in diameter were dissected free of stromal tissue, their diameter measured and classified under a stereomicroscope according to the criteria described by Kruip \& Dieleman (1982). Non-atretic follicles $\geqslant 10 \mathrm{~mm}$ in diameter were considered as preovulatory.

Calculations and statistics. A rise in a hormone concentration was considered to be a pulse when the value of 2 consecutive samples were greater than the mean of 2 previous samples (nadir) and the value of at least one of the peak samples exceeded the nadir by more than twice the coefficient of variation of the assay (McNeilly et al., 1984). The difference between the maximum value during a pulse and the nadir was considered as the pulse amplitude. Basal concentrations over a particular serial sampling period were calculated as the mean value of the lowest $25 \%$ of values over that period (McNeilly et al., 1984). Data were analysed by multivariate repeated measurements analysis (Srivastava \& Carter, 1983) on significance of treatment with PMSG, on day effect and on day $x$ treatment interactions with regard to the 3 frequent sampling periods. To preserve homogeneity of variance of the pulse frequency distribution, these data were transformed by taking the square root of the number of pulses observed in each sampling period.

\section{Results}

In all treated and control heifers the jugular blood concentration of progesterone fell to $<3.2 \mathrm{nmol} / \mathrm{l}$ after luteolysis. The vena cava blood concentration of progesterone was at least $2-3$ times higher than in jugular blood samples in all heifers during the luteal phase. This demonstrated that the tip of the catheter in each animal was correctly located in the caudal vena cava near the bifurcation with the vena ovarica.

Table 1. Numbers of follicles in the ovaries collected at $50 \mathrm{~h}$ after the onset of luteolysis in PMSG-treated and control heifers

\begin{tabular}{|c|c|c|c|c|c|c|c|c|c|}
\hline \multirow[b]{3}{*}{$\begin{array}{l}\text { Treated } \\
\text { heifers }\end{array}$} & \multicolumn{4}{|c|}{ Follicle diameter $(\mathrm{mm})$} & \multirow[b]{3}{*}{$\begin{array}{l}\text { Control } \\
\text { heifers }\end{array}$} & \multicolumn{4}{|c|}{ Follicle diameter $(\mathrm{mm})$} \\
\hline & \multicolumn{2}{|c|}{$>5<10$} & \multicolumn{2}{|c|}{$\geqslant 10$} & & \multicolumn{2}{|c|}{$>5<10$} & \multicolumn{2}{|c|}{$\geqslant 10$} \\
\hline & $\begin{array}{l}\text { Not } \\
\text { atretic }\end{array}$ & Atretic & $\begin{array}{c}\text { Not } \\
\text { atretic }\end{array}$ & Atretic & & $\begin{array}{c}\text { Not } \\
\text { atretic }\end{array}$ & Atretic & $\begin{array}{c}\text { Not } \\
\text { atretic }\end{array}$ & Atretic \\
\hline 1 & 4 & 1 & 3 & - & 7 & 1 & 2 & 1 & 1 \\
\hline 2 & 3 & - & 10 & 6 & 8 & 1 & 5 & 1 & - \\
\hline 3 & 5 & 5 & 8 & 3 & 9 & - & - & 1 & - \\
\hline 4 & 4 & 5 & 6 & 2 & 10 & - & - & 1 & - \\
\hline 5 & 1 & 1 & 2 & - & & & & & \\
\hline 6 & 4 & - & 1 & - & & & & & \\
\hline
\end{tabular}

Mean ( \pm s.e.m.) PMSG concentrations during the 3 sampling periods were $8.9 \pm 0.6$, $8.2 \pm 0.5,6.6 \pm 0.6,11.8 \pm 1 \cdot 26,7 \cdot 1 \pm 0.8$ and $6.2 \pm 0.8 \mu \mathrm{g} / 1$ in the treated heifers (Nos $1-6$ respectively). There was no correlation between the PMSG concentration and the number of 
Table 2. Effect of PMSG/PG treatment on the mean ( \pm s.e.m.) plasma concentration, pulse frequency and pulse amplitude of progesterone, androstenedione and oestradiol at 3 stages of the oestrous cycle

\begin{tabular}{|c|c|c|c|}
\hline Hormone & Day 10 & $\begin{array}{l}\text { Day of luteal } \\
\text { regression }\end{array}$ & $\begin{array}{l}1 \text { day after } \\
\text { luteal } \\
\text { regression }\end{array}$ \\
\hline \multicolumn{4}{|l|}{ Progesterone } \\
\hline \multicolumn{4}{|l|}{ Control $(N=4)$} \\
\hline Plasma (nmol/1) & \pm 4.7 & $16.2 \pm 3 \cdot 3$ & $2.7 \pm 0.6$ \\
\hline No. of pulses $/ 8 \mathrm{~h}$ & $7.3 \pm 0.9$ & $6.0 \pm 0.9$ & $4 \cdot 3 \pm 1 \cdot 0$ \\
\hline Amplitude (nmol/1) & $50.9 \pm 15.5$ & $10.6 \pm 4.0$ & $0.73 \pm 0.27$ \\
\hline \multicolumn{4}{|l|}{ Treated $(\mathrm{N}=6)$} \\
\hline Plasma (nmol/l) & $54 \cdot 1 \pm 5 \cdot 8$ & $19 \cdot 1 \pm 3 \cdot 0$ & $3.4 \pm 0.9$ \\
\hline No. of pulses $/ 8 \mathrm{~h}$ & $5.8 \pm 0.5$ & $3.8 \pm 1.2$ & $4.2 \pm 0.9$ \\
\hline Amplitude (nmol/1) & $34.4 \pm 6.7$ & $13.1 \pm 3.0$ & $2.8 \pm 1.8$ \\
\hline \multicolumn{4}{|l|}{ Androstenedione } \\
\hline \multicolumn{4}{|l|}{ Control $(\mathrm{N}=4)$} \\
\hline Plasma (nmol/1) & $0.26 \pm 0.02$ & $0.19 \pm 0.03$ & $0.14 \pm 0.01$ \\
\hline No. of pulses $/ 8 \mathrm{~h}$ & $7 \cdot 3 \pm 1 \cdot 1$ & $6.0 \pm 1.2$ & $6.8 \pm 1.0$ \\
\hline Amplitude (nmol/l) & $0.35 \pm 0.15$ & $0.15 \pm 0.03$ & $0.14 \pm 0.05$ \\
\hline \multicolumn{4}{|l|}{ Treated $(\mathrm{N}=6)$} \\
\hline Plasma (nmol/1) & $0 \cdot 20 \pm 0.02$ & $0.15 \pm 0.02$ & $0.11 \pm 0.02$ \\
\hline No. of pulses $/ 8 \mathrm{~h}$ & $6.0 \pm 0.3$ & $7.8 \pm 0.5$ & $6.4 \pm 0.7$ \\
\hline Amplitude (nmol/1) & $0.44 \pm 0.1$ & $0.14 \pm 0.04$ & $0.16 \pm 0.05$ \\
\hline \multicolumn{4}{|l|}{ Oestradiol } \\
\hline \multicolumn{4}{|l|}{ Control $(N=4)$} \\
\hline Plasma (pmol/1) & $1 \mathrm{I} \cdot 1 \pm 0.8$ & $38 \cdot 2 \pm 9 \cdot 6$ & \pm 14.8 \\
\hline No. of pulses $/ 8 \mathrm{~h}$ & $5 \cdot 3 \pm 1.0$ & $6.0 \pm 0.4$ & $6.8 \pm 0.9$ \\
\hline Amplitude (pmol/l) & $8 \cdot 2 \pm 2 \cdot 2$ & $19.8 \pm 4.4$ & $24.8 \pm 5.5$ \\
\hline \multicolumn{4}{|l|}{ Treated $(\mathrm{N}=6)$} \\
\hline Plasma (pmol/l) & $17 \cdot 1 \pm 3 \cdot 0$ & \pm 33.4 & \pm 86.4 \\
\hline No. of pulses $/ 8 \mathrm{~h}$ & $7.0 \pm 0.7$ & $8.2 \pm 0.6$ & $7.7 \pm 0.8$ \\
\hline Amplitude (pmol/l) & $27 \cdot 0 \pm 4 \cdot 1$ & $79.8 \pm 22.7$ & $169.2 \pm 68.7$ \\
\hline
\end{tabular}

pre-ovulatory follicles collected $50 \mathrm{~h}$ after the onset of luteal regression (Table 1). Also, the PMSG concentration and the total number of follicles $>5 \mathrm{~mm}$ in diameter were not correlated. From each heifer of the control group one preovulatory follicle was collected at $50 \mathrm{~h}$ after onset of luteal regression (Table 1).

Estimation of the LH concentration in jugular blood samples demonstrated that ovariectomy was performed in 2 treated heifers on the ascending limb of the preovulatory LH peak, in 2 on the descending limb, and in the other 2 treated and all control heifers before the occurrence of the LH peak.

\section{Pulsatile secretion patterns of steroids}

Episodic secretion patterns of progesterone in PMSG-treated cows were similar to controls with respect to the mean hormone concentration, the pulse frequency and the pulse amplitude (Table 2; Fig. 1). The concentration and the amplitude showed a significant $(P<0.001)$ day effect between the 1st and 2nd and between the 2nd and 3rd sampling period.

Administration of PMSG had no effect on the episodic release pattern of androstenedione (Table 2; Fig. 1). In treated and control heifers the concentration of the hormone and the pulse amplitude were decreased in the follicular phase, but pulse frequency was unaltered. There was a significant $(P=0.02)$ day effect for the plasma concentration between the 2 nd and 3rd sampling period. In some heifers of both groups extremely high values of androstenedione were measured in 


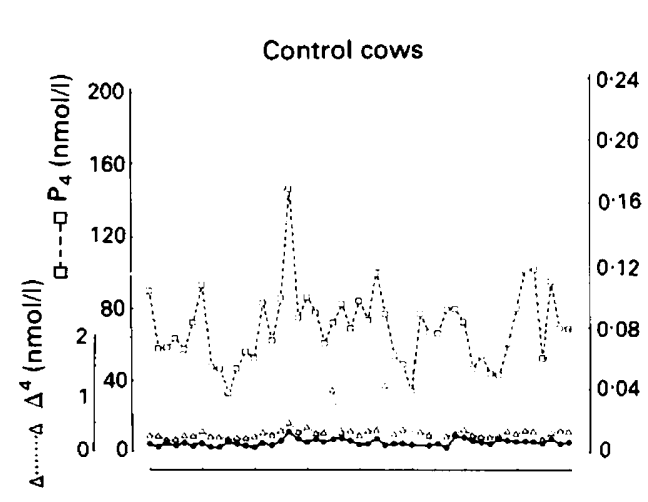

1

PMSG-treated cows
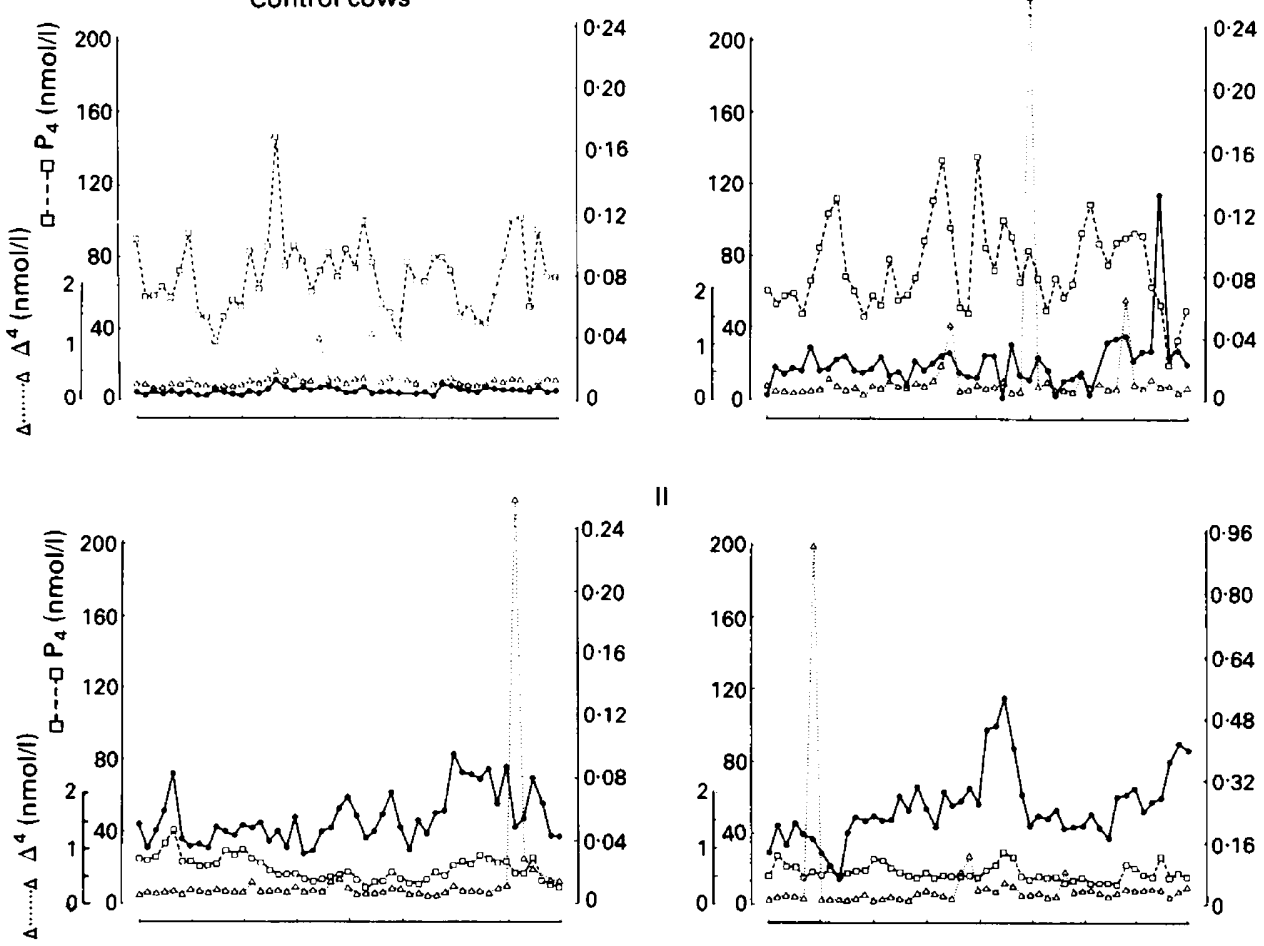

II
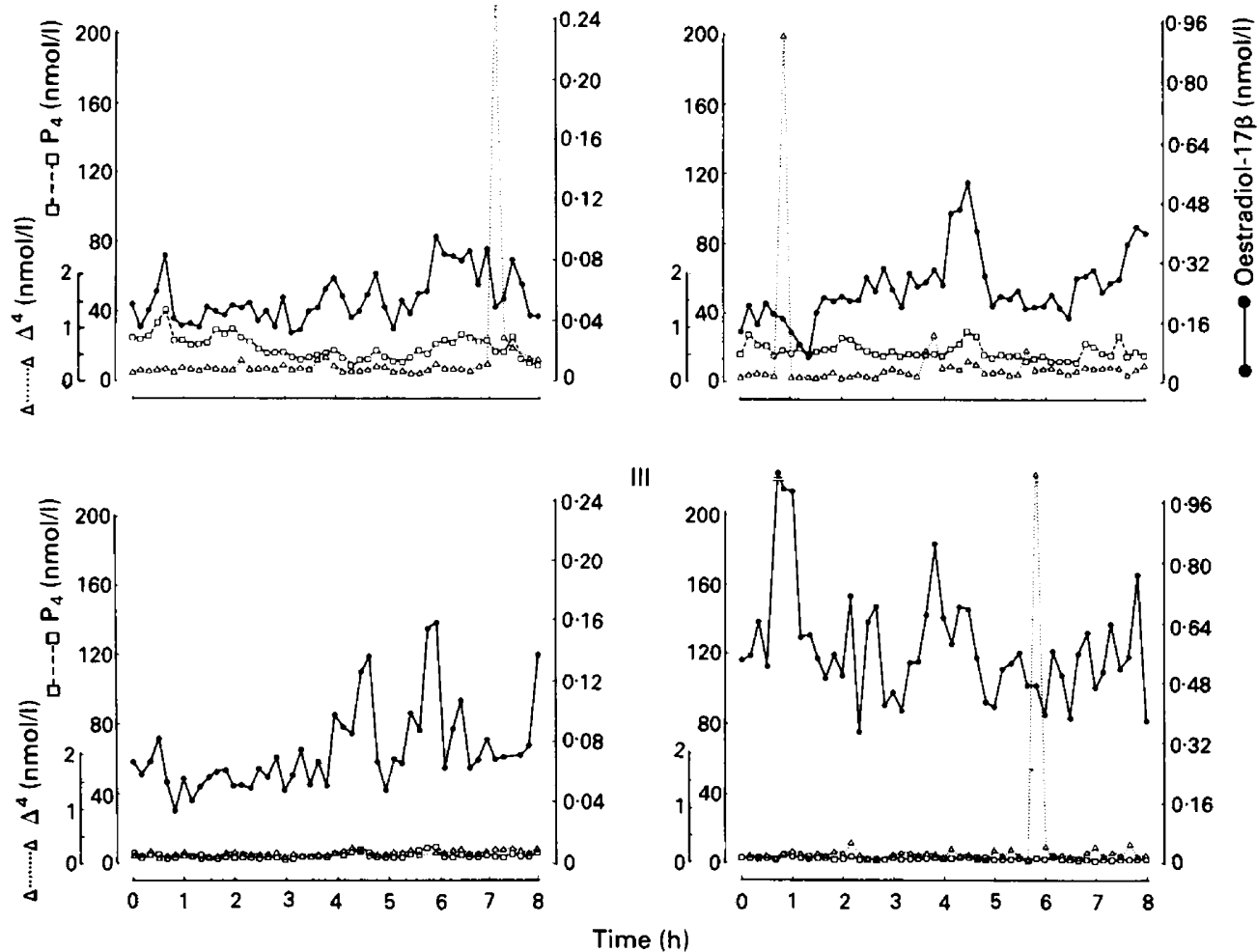

Fig. 1. Pulsatile secretion patterns of progesterone, oestradiol and androstenedione in a representative heifer of the control and of the PMSG-treated group. I, II and III represent the serial sampling periods of Day 10, during luteal regression and on the day thereafter respectively. $\mathrm{P}_{4}=$ progesterone, $\Delta^{4}=$ androstenedione.

1-3 isolated blood samples of a serial sampling period (Fig. 1). These values were not incorporated into the calculations of the parameters presented in Table 2. The androstenedione concentrations exceeded those of oestradiol except during the follicular phase in the treated heifers. The episodic secretion patterns of oestradiol in normally cyclic and PMSG-treated heifers were basically similar (Table 2; Fig. 1). However, plasma concentrations and amplitudes were much higher in the treated group, although both varied markedly among the treated heifers. The oestradiol concentration in the follicular serial sampling period was positively correlated $(r=0.82 ; P<0.05)$ with the number 


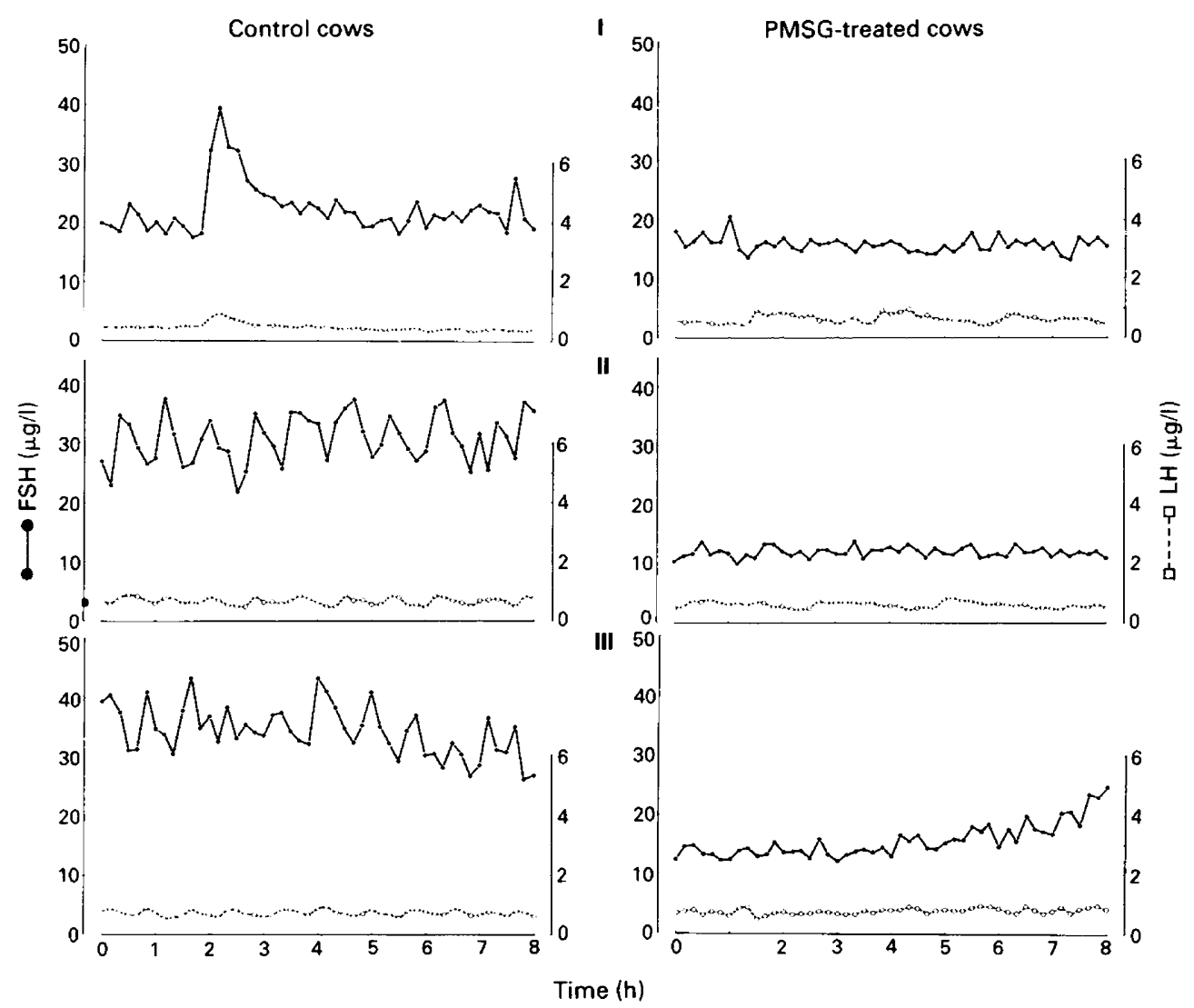

Fig. 2. Pulsatile secretion patterns of $\mathbf{L H}$ and FSH in a representative heifer of the control and of the PMSG-treated group. I, II and III represent the serial sampling periods on Day 10 , during luteal regression and on the day thereafter respectively.

of preovulatory follicles collected from each PMSG-treated heifer (Table 1). Plasma concentration and the pulse amplitude tended $(P<0 \cdot 1)$ to show a significant treatment effect. The plasma concentration also tended $(P<0 \cdot 1)$ to show a day effect. Differences in pulse frequency were significant $(P=0.01)$ with regard to treatment.

\section{Pulsatile secretion patterns of gonadotrophins}

The episodic release pattern of LH in control heifers (Table 3; Fig. 2) showed an increase in basal LH concentration after onset of luteolysis. An increase in the number of pulses occurred during luteal regression and the follicular phase whereas the mean pulse amplitude remained stationary. In PMSG-treated heifers the basal LH concentration remained unchanged in the successive sampling periods. Pulse frequency was suppressed during luteal regression and the follicular phase compared to the corresponding periods in control heifers. In treated and control heifers pulse amplitudes had similar magnitudes and they remained unchanged in the serial samplings. Pulse frequency data demonstrated a significant $(P=0.001)$ treatment effect, a significant $(P=0.03)$ day effect between the 1st and 2 nd sampling period and a significant $(P=0.03)$ day $\times$ treatment interaction effect between the 1 st and 2 nd and between the 2 nd and 3 rd sampling period. 
Table 3. Effect of PMSG/PG treatment on the mean ( \pm s.e.m.) plasma concentration, basal plasma concentration, pulse frequency and pulse amplitude of $\mathrm{LH}$ and FSH at 3 stages of the oestrous cycle

\begin{tabular}{|c|c|c|c|}
\hline Hormone & Day 10 & $\begin{array}{l}\text { Day of luteal } \\
\text { regression }\end{array}$ & $\begin{array}{l}1 \text { day after } \\
\text { luteal } \\
\text { regression }\end{array}$ \\
\hline \multicolumn{4}{|l|}{ LH } \\
\hline \multicolumn{4}{|l|}{ Control $(\mathrm{N}=4)$} \\
\hline Plasma $(\mu \mathrm{g} / 1)$ & $0.62 \pm 0.13$ & $0.88 \pm 0.08$ & $0.96 \pm 0.12$ \\
\hline Basal $(\mu \mathrm{g} / l)$ & $0.47 \pm 0.07$ & $0.67 \pm 0.07$ & $0.78 \pm 0.10$ \\
\hline No. of pulses $/ 8 \mathrm{~h}$ & $2 \cdot 0 \pm 0.4$ & $9.5 \pm 0.9$ & $7 \cdot 0 \pm 1.5$ \\
\hline Amplitude $(\mu \mathrm{g} / \mathrm{l})$ & $0.36 \pm 0.07$ & $0.32 \pm 0.04$ & $0.31 \pm 0.07$ \\
\hline \multicolumn{4}{|l|}{ Treated $(\mathrm{N}=6)$} \\
\hline Plasma $(\mu \mathrm{g} / 1)$ & $0.90 \pm 0.11$ & $0.94 \pm 0.11$ & $1.02 \pm 0.10$ \\
\hline Basal $(\mu \mathrm{g} / \mathrm{l})$ & $0.75 \pm 0.11$ & $0 \cdot 80 \pm 0 \cdot 11$ & $0.82 \pm 0.09$ \\
\hline No. of pulses $/ 8 \mathrm{~h}$ & $2.3 \pm 0.5$ & $3.2 \pm 0.7$ & $4.3 \pm 0.4$ \\
\hline Amplitude $(\mu \mathrm{g} / \mathrm{l})$ & $0.32 \pm 0.04$ & $0.33 \pm 0.02$ & $0.27 \pm 0.01$ \\
\hline \multicolumn{4}{|l|}{ FSH } \\
\hline \multicolumn{4}{|l|}{ Control $(\mathrm{N}=4)$} \\
\hline Plasma $(\mu \mathrm{g} / \mathrm{l})$ & $27.7 \pm 3.8$ & $34 \cdot 6 \pm 2 \cdot 4$ & $35.6 \pm 6.2$ \\
\hline Basal $(\mu \mathrm{g} / 1)$ & $23 \cdot 4 \pm 3 \cdot 3$ & $28.9 \pm 2 \cdot 1$ & $29 \cdot 1 \pm 5 \cdot 0$ \\
\hline No. of pulses $/ 8 \mathrm{~h}$ & $5.5 \pm 0.6$ & $10 \cdot 3 \pm 0 \cdot 3$ & $9 \cdot 3 \pm 0.3$ \\
\hline Amplitude $(\mu \mathrm{g} / 1)$ & $9 \cdot 2 \pm 1 \cdot 1$ & $10.0 \pm 0.8$ & $9.8 \pm 1.6$ \\
\hline \multicolumn{4}{|l|}{ Treated $(N=6)$} \\
\hline Plasma $(\mu \mathrm{g} / \mathrm{l})$ & $23 \cdot 1 \pm 2 \cdot 9$ & $15 \cdot 3 \pm 1 \cdot 5$ & $17.4 \pm 0.9$ \\
\hline Basal $(\mu \mathrm{g} / 1)$ & $20 \cdot 2 \pm 2 \cdot 8$ & $13 \cdot 3 \pm 1 \cdot 0$ & $13.8 \pm 0.9$ \\
\hline No. of pulses $/ 8 \mathrm{~h}$ & $5.2 \pm 0.6$ & $7.0 \pm 0.8$ & $7.5 \pm 0.4$ \\
\hline Amplitude $(\mu \mathrm{g} / \mathrm{l})$ & $6.3 \pm 1.6$ & $3.7 \pm 0.8$ & $4.7 \pm 0.8$ \\
\hline
\end{tabular}

Basal FSH concentration tended to increase after onset of luteal regression in control heifers (Table 3; Fig. 2). Pulse frequency increased after onset of luteolysis whereas pulse amplitude remained unchanged in the successive sampling periods. Administration of PMSG suppressed the basal FSH concentration in all heifers. Pulse amplitude remained almost unaltered. During luteal regression and the follicular phase pulse frequency was still higher than in the Day 10 period. All 3 FSH measures were suppressed after onset of luteal regression compared to corresponding periods in control heifers. For concentration and basal values there was a significant $(P<0.003)$ treatment effect and a significant $(P<0.01)$ day $\times$ treatment interaction effect between the 1st and 2 nd sampling period. The pulse amplitude data showed a significant $(P<0.01)$ effect with regard to treatment and tended $(P<0 \cdot 1)$ to show a day $\times$ treatment interaction effect between the first and second sampling period. FSH pulse frequency showed a significant $(P=0.03)$ treatment effect and a significant $(P<0.001)$ day effect between the 1 st and 2 nd sampling period.

\section{Discussion}

Administration of PMSG mainly affected the episodic release of oestradiol, FSH and LH whereas the secretion of progesterone and androstenedione seemed unaffected. The enhanced oestradiol secretion can be fully related to an increase in the number of presumptive preovulatory follicles which are the main source of oestradiol production. The significant correlation between both leads to this assumption. The markedly increased pulse amplitude together with the hardly changed pulse frequency point to a more or less concurrent pulsatile release of oestradiol by the individual follicles. Under physiological circumstances in the sheep, the pulsatile secretion of oestradiol is entirely dependent on the pulsatile secretion of LH (McNeilly et al., 1984). It appears, therefore, that PMSG in terms of LH activity did not overrule the endogenous LH secretion in this respect. 
However, PMSG treatment did result in a difference in pulse frequency for $\mathrm{LH}$ and oestradiol. This suggests that the synchrony between the LH and oestradiol pulsatile secretion as shown in the cow (Schallenberger et al., 1984) and the sheep (McNeilly et al., 1984) has been disturbed.

The finding that androstenedione concentrations exceeded those of oestradiol agrees with data from the ewe (Scaramuzzi \& Radford, 1983). In the cow, peripheral blood concentrations of androstenedione and oestradiol were reported to be similar during the follicular phase (McNatty et al., 1984). Since bovine follicles $>2 \mathrm{~mm}$ in diameter secrete androstenedione in the follicular fluid (McNatty et al., 1984) it is likely that the androstenedione concentration is the result of the accumulated secretion by several follicles. Androstenedione is the main substrate for the aromatase and thus the primary precursor for oestradiol synthesis by bovine granulosa cells (Dieleman \& Blankenstein, 1984). Oestradiol production and preovulatory follicular development are regulated by increases in LH activity which promotes androstenedione biosynthesis (Bogovich \& Richards, 1982). Therefore, the decrease in the androstenedione blood concentration during the follicular phase in treated as well as in control heifers can be related to increased oestradiol production by individual preovulatory follicles. This is supported by the higher concentrations of oestradiol, exceeding those of androstenedione, in follicular fluid of preovulatory follicles collected shortly before the LH surge (Dieleman et al., 1983b; Fortune \& Hansel, 1985; Bevers et al., 1988b). Our data with regard to androstenedione are in agreement with studies of Schenken \& Hodgen (1983) showing that hyperstimulation of follicular growth in monkeys by exogenous FSH had no effect on the peripheral blood concentrations of androstenedione.

The enhancement of basal LH concentrations and the considerable increase in pulse frequency after onset of luteal regression in normally cyclic cows are in accordance with previous studies (Rahe et al., 1980; Schallenberger et al., 1985). The tendency for basal FSH increase in the control cows during and after luteolysis differs from previous studies (Butler et al., 1983; Padmanabhan et al., 1984; Schallenberger et al., 1985) which report steady or declining levels. The increased pulse frequency confirms the observations of Schallenberger et al. (1985). Although in control cows increasing FSH concentrations were associated with increasing $\mathrm{LH}$ values, cross-reaction of $\mathrm{LH}$ in the FSH-RIA is probably not responsible for the FSH increase. Stimulation of follicular growth with PMSG severely affects endogenous gonadotrophin secretion. Generally, our data demonstrate suppression of basal secretion, pulse frequency and pulse amplitude of FSH and suppression of pulse frequency of LH. Numerous studies in sheep and cows (McNeilly, 1984; Clarke et al., 1986; Martin et al., 1986, 1988; Quirk \& Fortune, 1986; Tsonis et al., 1988) have shown that inhibin and oestradiol in synergistic co-operation are responsible for the negative ovarian feed-back on FSH secretion. It may be assumed that the suppression of FSH in PMSG-stimulated cows is caused by the strongly increased concentrations of oestradiol and probably also inhibin due to the enhanced number of preovulatory follicles. In the ewe there is evidence that administered FSH increases the secretion of inhibin in ovarian venous plasma (Tsonis et al., 1988).

The effects of PMSG on the pulsatile secretion of LH are complex and difficult to interpret. On the one hand a significant reduction in pulse frequency is obtained, whereas on the other the LH surge is elicited earlier than in normally cyclic cows in at least 4 of 6 cows in this experiment, which is in accordance with previous data (Bevers \& Dieleman, 1987). In sheep and cows, oestradiol inhibits LH pulse amplitude and progesterone inhibits pulse frequency (Goodman \& Karsch, 1980; McNeilly et al., 1984; Schallenberger et al., 1984). This largely accounts for the increased pulse frequency after onset of luteal regression in normally cyclic animals. The decreased pulse frequency, a variable solely under hypothalamic control (Martin et al., 1987), in PMSG-treated cows might be caused by an inhibition of GnRH release, through an effect on the hypothalamus. This cannot be related to negative feed-back of progesterone, since treated heifers showed the same progesterone pattern during luteolysis and thereafter as did the normally cyclic heifers. Inhibin should be excluded as well. It hardly affects the secretion of LH (McNeilly, 1984; Quirk \& Fortune, 1986; Martin et al., 1988) except for some attenuation of the pulse amplitude (Clarke et al., 1986) through an inhibitory effect at the pituitary level. However, the feed-back action of oestradiol on 
the hypothalamic and the pituitary level with regard to $\mathrm{LH}$ release appears to be a complicated balance between inhibition and stimulation which has not been fully clarified. Presumably, disturbance of this balance by the sustained high concentration of oestradiol in PMSG-stimulated cows might have resulted in suppression of LH pulse frequency and accelerated occurrence of the preovulatory LH peak. Why the LH peak does not occur in about $20 \%$ of the PMSG-stimulated cows (Bevers \& Dieleman, 1987; Callesen et al., 1987) is not yet clear. Deviations in concentrations of PMSG, cortisol or prolactin are not responsible for a missing LH surge (Bevers \& Dieleman, 1987). It is possible that a so-called gonadotrophin-surge inhibiting factor, as demonstrated in the sow (Danforth et al. 1987), is also secreted by developing bovine follicles.

This study concentrated on the pulsatile hormone secretion in PMSG-stimulated cows before the occurrence of the preovulatory LH peak, showing suppressed pulsatile secretion of the endogenous gonadotrophins and an enhanced oestradiol concentration. Whether these aberrations adversely affect preovulatory follicular development and oocyte maturation, and thus contribute to the variation in viable embryo yield after superovulation, remain to be investigated.

We thank Dr P. Fontijne and Professor Dr G. C. van der Weyden and assistants for surgery; Mr Th. H. van Beneden and Mr A. V. P. van de Poll for technical assistance; Mr S. H. J. Mook and his assistants for tending the animals; $\mathrm{Mr}$ W. Bes for drawing the figures; Intervet International bv. for supplying Folligon and Prosolvin and financially supporting the project; the NIAMDD for supplying NIH-P-B3 and NIH-LH-B4; and Dr K. W. Cheng, University of Manitoba, for the bovine FSH HS-2-17 preparation and the FSH antiserum.

\section{References}

Bevers, M.M. \& Dieleman, S.J. (1987) Superovulation of cows with PMSG: Variation in plasma concentrations of progesterone, oestradiol, LH, cortisol, prolactin and PMSG and in number of preovulatory follicles. Anim. Reprod. Sci. 15, 37-52.

Bevers, M.M., Dieleman, S.J., van Tol, H.T.M. \& Blankenstein, D.M. (1988a) Aberrations in gonadotrophin hormone secretion in PMSG-superovulated cows. Proc. Ilth Int. Congr. Anim. Reprod. \& A.I., Dublin VI, pp. 141.

Bevers, M.M., Dieleman, S.J. \& Kruip, Th.A.M. (1988b) Chronic treatment with bromocryptine during the oestrous cycle of the cow: evidence that prolactin is not involved in preovulatory follicular growth. Anim. Reprod. Sci. 17, 21-32.

Bogovich, K. \& Richards, J.S. (1982) Androgen biosynthesis in developing ovarian follicles: evidence that luteinizing hormone regulates thecal $17 \alpha$-hydroxylase and $\mathrm{C}_{17-20}$-lyase activities. Endocrinology 111, $1201-1209$.

Butler, W.R., Katz, L.S., Arriola, J., Milvae, R.A. \& Foote, R.H. (1983) On the negative feedback regulation of gonadotrophins in castrate and intact cattle with comparison of two FSH radioimmunoassays. $J$. Anim. Sci. 56, 919-929.

Callesen, H., Greve, T. \& Hyttel, P. (1987) Premature ovulations in superovulated cattle. Theriogenology 28, $155-166$.

Cheng, K.W. (1978) Development and characterization of a homologous radioimmunoassay for bovine follicle stimulating hormone. J. Endocr. 77, 185-193.

Clarke, I.J., Findlay, J.K., Cummins, J.T. \& Ewens, W.J. (1986) Effects of ovine follicular fluid on plasma $\mathrm{LH}$ and FSH secretion in ovariectomized ewes to indicate the site of action of inhibin. J. Reprod. Fert. 77, $575-585$.

Danforth, D.R., Sinosich, M.J., Anderson, T.L., Cheng, C.Y., Bardin, C.W. \& Hodgen, G.D. (1987) Identification of gonadotrophin surge-inhibiting factor in follicular fluid and its differentiation from inhibin. Biol. Reprod. 37, 1075-1082.

Dieleman, S.J. \& Bevers, M.M. (1987) Effects of monoclonal antibody against PMSG administered shortly after the preovulatory LH surge on time and number of ovulations in PMSG/PG-treated cows. J. Reprod. Fert. 81, 533-542.

Dieleman, S.J. \& Blankenstein, D.M. (1984) Changes in oestrogen-synthesizing ability of preovulatory bovine follicles relative to the peak of LH. J. Reprod. Fert. 72, 487-494.

Dieleman, S.J. \& Kruip, Th.A.M. (1980) Relation between 3B-hydroxysteroid dehydrogenase activity in bovine preovulatory follicles and steroids present in the follicular fluid during normal and PMSG/ PGF2A-induced oestrus. Proc. 9th Int. Congr. Anim. Reprod. \& A.I., Madrid VI, pp. 9093.

Dieleman, S.J., Kruip, Th.A.M., Fontijne, P., de Jong, W.H.R. \& van der Weyden, G.C. (1983a) Changes in oestradiol, progesterone and testosterone concentrations in follicular fluid and in the micromorphology of preovulatory bovine follicles relative to the peak of luteinizing hormone. J. Endocr. 97, $31-42$.

Dieleman, S.J., Bevers, M.M., Poortman, J. \& van Tol, H.T.M. (1983b) Steroid and pituitary hormone concentrations in the fluid of preovulatory bovine follicles relative to the peak of $\mathrm{LH}$ in the peripheral blood. J. Reprod. Fert. 69, 641-649. 
Dieleman, S.J., Bevers, M.M., van Tol, H.T.M. \& Willemse, A.H. (1986) Peripheral plasma concentrations of oestradiol, progesterone, cortisol, LH and prolactin during the oestrous cycle in the cow, with emphasis on the peri-oestrous period. Anim. Reprod. Sci. 10, 275-292.

Dieleman, S.J., Bevers, M.M., Wurth, Y.A., Gielen, J.Th. \& Willemse, A.H. (1989) Improved embryo yield and conditions of ovaries in cows after PMSG superovulation with monoclonal anti-PMSG administration shortly after the preovulatory LH peak. Theriogenology 31, 473-488.

Fortune, J.E. \& Hansel, W. (1985) Concentrations of steroids and gonadotrophins in follicular fluid from normal heifers and heifers primed for superovulation. Biol. Reprod. 32, 1069-1079.

Goodman, R.L. \& Karsch, F.J. (1980) Pulsatile secretion of luteinizing hormone: differential suppression of luteinizing hormone by estradiol and progesterone. Endocrinology 107, 1286-1290.

Kruip, Th.A.M. \& Dieleman, S.J. (1982) Macroscopic classification of bovine follicles and its validation by micromorphological and steroid biochemical procedures. Reprod. Nutr. Develop. 22, 465-473.

Martin, G.B., Wallace, J.M., Taylor, P.L., Fraser, H.M., Tsonis, C.G. \& McNeilly, A.S. (1986) The roles of inhibin and gonadotrophin-releasing hormone in the control of gonadotrophin secretion in the ewe. $J$. Endocr. 111, 287-296.

Martin, G.B., Taylor, P.L. \& McNeilly, A.S. (1987) Effect of small doses of bovine follicular fluid on the tonic secretion of gonadotrophins in the ewe. $J$. Endocr. 114, 73-79.

Martin, G.B., Price, C.A., Thiery, J.-C. \& Webb, R. (1988) Interactions between inhibin, oestradiol and progesterone in the control of gonadotrophin secretion in the ewe. $J$. Reprod. Fert. 82, 319-328.

McNatty, K.P., Heath, D.A., Henderson, K.M., Lun, S., Hurst, P.R., Ellis, L.M., Montgomery, G.W., Morrison, L. \& Thurly, D.C. (1984) Some aspects of thecal and granulosa cell function during follicular development in the bovine ovary. J. Reprod. Fert. 72, 39-53.

McNeilly, A.S. (1984) Changes in FSH and the pulsatile secretion of LH during the delay in oestrus induced by treatment of ewes with bovine follicular fluid. $J$. Reprod. Fert. 72, 165-172.

McNeilly, A.S., Fraser, H.M. \& Baird, D.T. (1984) Effect of immunoneutralization of $\mathrm{LH}$ releasing hormone on LH, FSH and ovarian steroid secretion in the preovulatory phase of the oestrous cycle of the ewe. J. Endocr. 101, 213-219.

Monniaux, D., Chupin, D. \& Saumande, J. (1983) Superovulatory responses of cattle. Theriogenology 19, $55-80$.

Moor, R.M., Kruip, Th.A.M. \& Green, D. (1984) Intra-ovarian control of folliculogenesis: Limits to superovulation. Theriogenology 21, 103-116.
Padmanabhan, V., Convey, E.M., Roche, J.F. \& Ireland, J.J. (1984) Changes in inhibin-like bioactivity in ovulatory and atretic follicles and utero-ovarian venous blood after prostaglandin-induced luteolysis in heifers. Endocrinology 115, 1332-1340.

Quirk, S.M. \& Fortune, J.E. (1986) Plasma concentrations of gonadotrophins, preovulatory follicular development and luteal function associated with bovine follicular fluid-induced delay of oestrus in heifers. J. Reprod. Fert. 76, 609-621.

Rahe, C.H., Owens, R.E., Fleeger, J.L., Newton, H.J. \& Harms, P.G. (1980) Pattern of plasma luteinizing hormone in the cyclic cow: dependence upon the period of the cycle. Endocrinology 107, 498-503.

Saumande, J. (1980) Concentrations of luteinizing hormone, oestradiol- $17 \beta$ and progesterone in the plasma of heifers treated to induce superovulation. $J$. Endocr. 84, 425-437.

Scaramuzzi, R.J. \& Radford, H.M. (1983) Factors regulating ovulation rate in the ewe. J. Reprod. Fert. 69, 353-367.

Schallenberger, E., Schams, D., Bullermann, B. \& Walters, D.L. (1984) Pulsatile secretion of gonadotrophins, ovarian steroids and ovarian oxytocin during prostaglandin-induced regression of the corpus luteum in the cow. J. Reprod. Fert. 71, 493-501.

Schallenberger, E., Schondorfer, A.M. \& Walters, D.L. (1985) Gonadotrophins and ovarian steroids in cattle. I. Pulsatile changes of concentrations in the jugular vein throughout the oestrous cycle. Acta endocr., Copenh. 108, 312-321.

Schams, D., Menzer, Ch., Schallenberger, E., Hoffman, B. \& Hahn, R. (1978) Some studies on pregnant mare serum gonadotrophin (PMSG) and on endocrine responses after application for superovulation in cattle. In Control of Reproduction in the Cow, pp. 122-143. Ed. J. M. Sreenan. Martinus Nijhoff, The Hague.

Schenken, R.S. \& Hodgen, G.D. (1983) Follicle-stimulating hormone induced ovarian hyperstimulation in monkeys: blockade of the luteinizing hormone surge. J. clin. Endocr. Metab. 57, 50-55.

Srivastava, M.S. \& Carter, E.M. (1983) An Introduction to Applied Multivariate Statistics. Elseviers Science Publ., New York.

Tsonis, C.G., McNeilly, A.S. \& Baird, D.T. (1988) Inhibin secretion by the sheep ovary during the luteal and follicular phases of the oestrous cycle and following stimulation with FSH. J. Endocr. 117, 283-291.

Walters, D.L., Schams, D. \& Schallenberger, E. (1984) Pulsatile secretion of gonadotrophins, ovarian steroids and ovarian oxytocin during the luteal phase of the oestrous cycle in the cow. J. Reprod. Fert. 71, $479-491$.

Received 29 March 1989 